\title{
Perceptual Correlates of Changes in Cortical Representation of Fingers in Blind Multifinger Braille Readers
}

\author{
Annette Sterr, ${ }^{1}$ Matthias M. Müller, ${ }^{1}$ Thomas Elbert, ${ }^{1}$ Brigitte Rockstroh, ${ }^{1}$ Christo Pantev, ${ }^{2}$ and Edward Taub ${ }^{3}$ \\ ${ }^{1}$ Department of Psychology, University of Konstanz, Fach D25, D-78457 Konstanz, Germany, 2Institute of Experimental \\ Audiology, University of Münster, D-48129 Münster, Germany, and ${ }^{3}$ Department of Psychology, University of Alabama at \\ Birmingham, Birmingham, Alabama 35294
}

The mature mammalian nervous system alters its functional organization in a use-dependent manner. Enhanced stimulation of a body part enlarges its cortical representational zones and may change its topographic order. Little is known about the perceptual and behavioral relevance of these plastic alterations in cortical organization. We used blind Braille readers who use several fingers on each hand and who do so for many hours each day as a model to investigate this issue. Magnetic source imaging indicated that the cortical somatosensory representation of the fingers was frequently topographically disordered in these subjects; in addition, they frequently misperceived which of these fingers was being touched by a light tactile stimulus. In contrast, neither the disordered representation nor mislocalizations were observed in sighted controls. Blind non-teacher Braille readers who used only one finger for reading were not significantly different from the sighted controls. Thus, usedependent cortical reorganization can be associated with functionally relevant changes in the perceptual and behavioral capacities of the individual.

Key words: blindness; Braille reading; cortical reorganization; somatosensory; sensory deafferentation; tactile perception; cortex; organization; Semmes-Weinstein monofilaments
In the somatosensory system, cortical reorganization occurs after both increased sensory input to a portion of the brain (Jenkins et al., 1990; Recanzone et al., 1992a,-c) and decreased sensory input produced by either deafferentation (Pons et al., 1991) or amputation (Merzenich et al., 1984; Yang et al., 1994; Elbert et al., 1994; Flor et al., 1995). Decreased input has been shown to be correlated with outcomes of functional relevance to the experience of an individual. Thus, after upper extremity amputation or deafferentation, the portion of the brain representing the now absent body part is "taken over" by adjacent cortical regions representing portions of the body with intact input (Pons et al., 1991; Elbert et al., 1994; Florence and Kaas, 1995). Flor et al. (1995) found that the amount of this cortical reorganization was highly correlated with phantom limb pain. This result has been replicated in a number of subsequent studies using MEG, EEG, and magnetic resonance imaging (Knecht et al., 1996; Birbaumer et al., 1997). In the auditory system, the amount of cortical reorganization has been found to have a strong relationship to tinnitus (Mühlnickel et al., 1998). In addition, the increased use of the digits occurring in musical practice has been found to be associated with focal dystonia in professional musicians (Elbert et al., 1996).

Use-dependent expansion of cortical somatosensory representation in area $3 \mathrm{~b}$ is correlated, of course, with the increase in the

Received Dec. 29, 1997; revised March 2, 1998; accepted March 25, 1998.

This work was supported by Biomagnetic Technologies Inc., a grant from the Deutsche Forschungsgemeinschaft to T.E., and a grant from the Rehabilitation Research Service of the Veterans Administration (B95-975R) to E.T.

Part of this work was carried out at the Scripps Clinic and Research Foundation, La Jolla, CA.

We are grateful to the staff members of the San Diego Center for the Blind and the Braille Institute La Jolla for referring participants. We thank Patti Quint, Lacey Kurelowech, and Joslyne Foley for technical assistance.

Correspondence should be addressed to A. Sterr, University of Konstanz, Department of Psychology, 78457 Konstanz, Germany.

Copyright (C) 1998 Society for Neuroscience $\quad 0270-6474 / 98 / 184417-07 \$ 05.00 / 0$ sensory stimulation that produced it, but this increased cortical representation has not been shown to be otherwise correlated with additional functionally relevant changes in the perceptual or behavioral capacities of humans, as opposed to the case of inputdecrease cortical reorganization after amputation. There is suggestive evidence that this is the case (Elbert et al., 1995, 1997; Rockstroh et al., 1998), but there has not yet been a direct demonstration.

The extent of somatosensory cortical representation of the digits has been demonstrated to be dependent on the amount and type of sensory input arriving in the primary somatosensory cortex. Elbert and coworkers (1995), pursuing in humans the seminal work of Jenkins, Merzenich, and Recanzone and their associates carried out with new world monkeys (Jenkins et al., 1990; Recanzone et al., 1990, 1992a-c), used magnetic source imaging to show that the somatosensory cortical representation of the left hand of string players, which engages in the complex and demanding task of fingering the strings, is significantly expanded. Pascual-Leone and co-workers (1993), examining a related issue, used transcranial magnetic stimulation to demonstrate in blind Braille readers that the motor representation of the reading finger is expanded. A number of studies have been carried out concerning the factors determining the discreteness of the topographic representation of the fingers in the homuncular map of the somatosensory cortex. The surgical joining of two digits in owl monkeys was found several months later to have resulted in the fusion of the cortical representation of the syndactylous digits (Clark et al., 1988; Allard et al., 1991), whereas the opposite intervention, surgical separation of syndactylous digits, was found to lead to a corresponding separation of the somatosensory cortical representation of the digits in humans (Mogilner et al., 1993). The hypothesis that the fusion of cortical representations was caused by the increase in simultaneity of somatosensory inputs when digits are joined (Clark et al., 1988; Allard et al., 1991) 
received support from two experiments with owl monkeys from the same laboratory showing that (1) prolonged simultaneous stimulation of three fingers led to the development of cortical neuronal receptive fields spanning all three digits, a phenomenon not observed to occur in control animals (Wang et al., 1995), and (2) sustained, repetitive gripping under conditions of high force and vibration led to "digit representations (that) were geographically disorganized” (Byl et al., 1996, 1997).

On the basis of the hypothesis that the fusion of cortical representations is caused by increased simultaneity of sensory inputs, we tested the somatotopic representations of blind Braille readers who (1) used three fingers (digits $2,3,4$ ) simultaneously for reading and, (2) as instructors of the method, typically engaged in this practice several hours daily. We also tested blind Braille readers who use one finger and sighted non-Braille reading subjects. The cited literature suggests that three-finger reading should lead to both an expansion of the cortical representation of these fingers and an alteration in their topographic arrangement. If this is the case, one may ask whether such cortical reorganizational changes might in turn be correlated with significant perceptual changes, and if so would the cortical and perceptual alterations bear a meaningful relationship to one another?

A brief account of these results has been published previously (Sterr et al., 1998).

\section{MATERIALS AND METHODS}

Stimuli. Stimulation consisted of light superficial pressure applied by means of a pneumatic stimulator using a standard, nonpainf ul stimulation intensity (for more details, see Elbert et al., 1994). Tactile stimulation was delivered to the midvolar aspect of the distal phalanx of left and right D1, D2, D5, and right and left corners of the lower lip (LL). At each site, 512 stimuli were delivered at a rate of $3.3 / \mathrm{sec}$. Stimulation site sequence was varied according to a fixed irregular order across subjects.

Subjects. All subjects were right-hand dominant. Four blind threefinger Braille readers ( $35 \pm 10$ years), six blind one-finger Braille readers (48 \pm 8 years), and five sighted non-Braille-reading persons $(35 \pm 7$ years) participated in the study. The three-finger Braille readers worked as Braille instructors, using Braille daily for 2-6 hours. For reading they used both index fingers (D2) to decode the dot pattern, the middle fingers (D3) to detect the spaces between the distinct Braille signs, and the fourth fingers (D4) to keep track of the line. The blind subjects had lost sight because of diseases affecting the peripheral components of the visual system and were selected for not having any further neurological problems. Light perception was present in two cases; the remainder of the subjects had no residual vision. Three of the three-finger readers had lost vision at birth because of retinal disease and had studied Braille in school beginning at age 5 years. One three-finger reader became blind at age 16 years as a result of optic nerve atrophy; she had used Braille for 10 years at the time of recording. Four of the one-finger readers used one index finger for reading (three right D2, one left D2), and two readers used both index fingers. Three of these readers were congenitally blind and read Braille since age 6 years. Two one-finger readers suffered from visual impairment attributable to progressive retinal disease and became entirely blind at age 20 and 23 years, whereas a sixth subject became blind as a result of optic nerve transection at age 30 years. At the time of the experiment the latter subjects had been reading Braille for 25, 35, and 16 years, respectively. All five sighted subjects were members of the university staff. The protocol was approved by the institution's review board, and subjects gave informed consent after hearing a description of the study.

Recordings. Magnetic fields were recorded in a magnetically shielded room using a 37-channel magnetometer (Magnes, BTi, San Diego, CA) with a sampling rate of $297.6 \mathrm{~Hz}$. The sensor array was positioned over the hemisphere contralateral to the side of stimulation (centered at $\mathrm{C} 3$ or C4) and evoked magnetic fields were obtained by on-line averaging.

Sensory testing. After the MEG recording, the sensory thresholds of the fingertips were determined using a von Frey-type aesthesiometer (Semmes-Weinstein-Monofilaments, model \#16010, Lafayette Instruments Company). Participants were instructed to indicate verbally when the touch was felt. Stimulation consisted of pressing a von Frey hair gently against the skin until it just began to bend. A stimulus of a given strength was applied to the midvolar surface of the distal phalanx of each of the digits of one of the hands in random order; sighted subjects were required to keep eyes closed. Each hand was tested separately; thresholds for each finger were determined twice by the method of limits, using stimulus series of increasing and decreasing strengths. Counterbalancing was used for direction of stimulus series both within and between subjects and for order of the hand that was tested first. Ten to $15 \mathrm{~min}$ after threshold determination, the ability to correctly identify which finger was being touched was determined, starting with the originally tested hand. The threshold von Frey hair stimulus for each subject (von Frey hair strengths: $2.44-2.83$ ) was applied to each digit five times in a fixed irregular order with an interstimulus interval of 1-2 sec. The same hand was then tested in the same fashion at one von Frey hair strength subthreshold and at one or more steps above threshold until the digital location of stimulation was correctly identified on each trial. The same testing procedure was then carried out for the opposite hand. For tabulation purposes, a hand was characterized as exhibiting mislocalization if incorrect localization occurred for at least one finger on at least two out of five trials at the threshold stimulation value.

Data analysis. The averaged evoked magnetic field data were digitally filtered using a second order bandpass filter $(3-30 \mathrm{~Hz})$. Within the range of 30-70 msec after stimulus onset, a first major peak was identified in each of the evoked waveforms. For each evoked magnetic field, a single equivalent current dipole (ECD) model (best individually fitting local sphere) was fitted, and the medians of the dipole moment and the dipole location for the peak in the signal power (root mean square across channels) were computed, if the following requirements were met: (1) a signal-to-noise ratio $>4,(2)$ a goodness of fit of the ECD model to the measured field $>0.95$, and (3) a minimal confidence volume of the ECD location $<300 \mathrm{~mm}^{3}$. The Euclidean distance and the distance in the three separate dimensions were calculated between the centers of cortical responsivity to tactile stimulation of each of the digits (D1-D2, D1-D5, and D2-D5) and of each digit and the ipsilateral lower lip (D1-LL, D2-LL, and D5-LL).

To obtain an estimate of the cortical topographic order/disorder of the somatotopic organization, all topographic arrangements in which the cortical representation of the digits was in the correct order in the inferior-superior dimension $(\mathrm{D} 1 \rightarrow \mathrm{D} 2 \rightarrow \mathrm{D} 5)$ were assigned a value of zero. If there was topographic disorder in any pair of cortical digital representations (D1-D2, D2-D5, or D1-D5), each of the distances in the deviant direction was summed and placed in the numerator of a fraction whose denominator was the distance between representations of the two fingers most distant from one another. Using the size of the cortical representation of the hand as a denominator serves to correct for the fact that there was an expansion of the hand representation in the three-finger blind Braille readers; without this correction the amount of cortical disorder would be overestimated for this group. The measure can be calculated as follows:

cortical disorder

$$
=\frac{[\text { deviance }(\mathrm{D} 1-\mathrm{D} 2)]+[\operatorname{deviance}(\mathrm{D} 1-\mathrm{D} 5)]}{\text { distance between farthest apart finger representations }} .
$$

For all dependent variables, ANOVAs or $t$ tests (two-tailed) were calculated. Post hoc comparisons were conducted by Scheffé tests.

\section{RESULTS}

\section{Evoked magnetic fields and dipole localizations}

No obvious differences were observed between the wave forms elicited in the three groups (Fig. 1). For the first major peak, average latencies ranged between 52 and $54 \mathrm{msec}$ for the different fingers, but were significantly shorter for the lip (37 msec; $F_{(3,27)}$ $=17.0 ; p<0.01)$. Average amplitudes were 53-81 fT; corresponding dipole moments had an average strength of 10.3-13.9 $\mathrm{nAm}$. There was no difference in latencies or response amplitudes between the groups for any of the stimulation locations (ANOVAs).

We observed a substantial difference in the size of the hand representation between the groups $\left(F_{(2,12)}=16.6 ; p<0.001\right)$ 

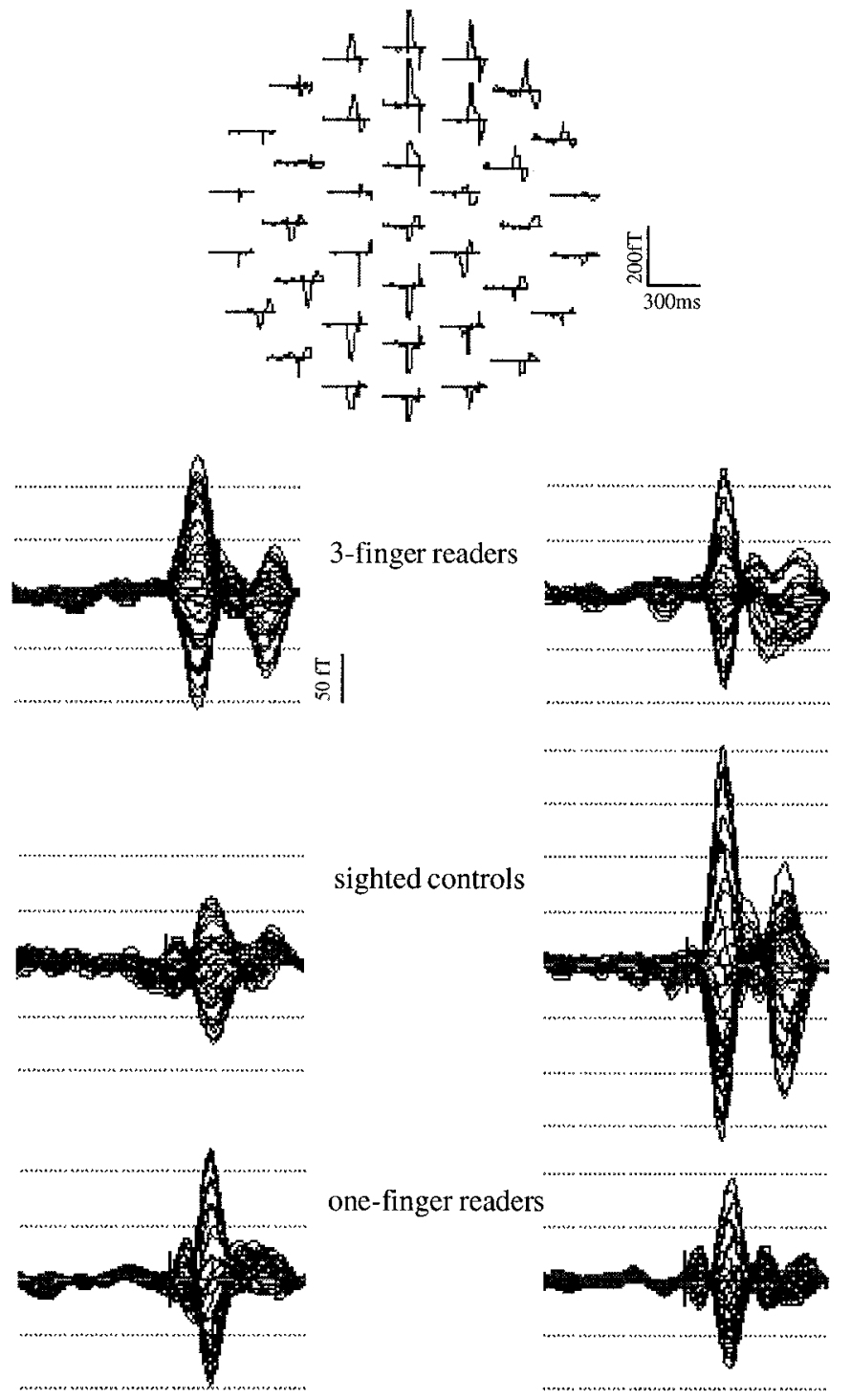

Figure 1. Set of individual waveforms indicating the magnetically evoked responses for stimulation of the right index finger of two members of each group: three-finger blind Braille readers, one-finger blind Braille readers, and sighted controls.

(Fig. 2). The size of the hand representation was measured as the distance between the representations of the digits that were farthest apart in the inferior-superior dimension (medial-lateral dimension on the surface of the cortex) (Fig. 2A). The hand representation for the three-finger readers was greatly enlarged, measuring $14 \mathrm{~mm}$ compared with $8 \mathrm{~mm}$ in one-finger readers and $7 \mathrm{~mm}$ for the sighted controls. The difference between the threefinger readers and both the one-finger readers and the sighted controls was significant (three-finger vs one-finger readers: $t=$ $4.4, p<0.001$; three-finger readers vs controls: $t=6.0, p<0.001$ ), but the latter two groups were not significantly different from one another.

Similarly, the Euclidean distances in three-dimensional space between the three digit locations were significantly greater in the three-finger readers than in the controls $\left(F_{(1,7)}=13.1 ; p<0.001\right)$ and in the one-finger readers $\left(F_{(1,8)}=8.7 ; p<0.05\right)$ (Fig. $\left.2 B\right)$. Finally, in all four one-finger readers who used just one hand, there was a substantial increase in the dipole strength of the reading D2 compared with the nonreading D2 (18.7 $\pm 7.0 \mathrm{nAm}$ vs $9.2 \pm 1.6 \mathrm{nAm})$, suggesting that there was an expansion of the reading D2 (Fig. 3). The laterality coefficient of the dipole strength $Q$ of the reading $\mathrm{D} 2$ compared to the non-reading $\mathrm{D} 2\left\{\left(\mathrm{Q}_{\text {reading }}-\mathrm{Q}_{\text {nonreading }}\right) /\left[\left(\mathrm{Q}_{\text {reading }}+\mathrm{Q}_{\text {nonreading }}\right) / 2\right]\right\}$ was 0.63 $(t=3.7 ; p<0.05)$. The right-left difference in the dipole moment for the two D2s in sighted subjects was not significant (laterality coefficient $=0.07)$. This comparison was not relevant for the three-finger readers because they all read with both hands, although there was a tendency to relay more heavily on the leading right hand, which may be reflected in the nonsignificant difference in the figure.

\section{Cortical somatotopic organization}

The analysis of the topographic order of the cortical representation of the digits revealed a significant difference between the three groups $\left(F_{(2,12)}=11.53 ; p=0.002\right)$. In each sighted subject, the expected homuncular pattern was observed, with D1 being in the most inferior (lateral) position, D2 being more medial, and D5 being in the most superior (medial) position (Fig. 4). In each of the three-finger Braille readers, this pattern of finger representation was changed in at least one of the hemispheres (Fig. 4). The three-finger blind Braille readers differed significantly from the one-finger readers in the amount of cortical digital topographic disorder (post hoc Scheffé test, $p=0.007$ ) and from the sighted subjects $(p=0.003)$. The one-finger readers and sighted subjects did not differ significantly from one another. In the one-finger Braille readers, the cortical topography of finger representations was disordered in only one of six subjects (Fig. 4), and for the three-finger readers each subject exhibited topographic disorder in at least one hemisphere. For the three-finger readers the disordered topography was in the left hemisphere for two subjects, the right hemisphere for one subject, and both hemispheres for one subject. Thus, five of eight possible hemispheres showed a disordered topographic arrangement of the fingers. In three cases, the D1 representation was medial to one or both of the other two digits, whereas in the other two cases, D2 and D5 were in reversed order.

\section{Sensory thresholds and digital mislocalization}

The reading fingers of the blind Braille readers had lower tactile thresholds than did the homologous fingers of the sighted subjects. When all fingers were included in the analyses, blind persons tended to have lower sensory thresholds than sighted controls $(t=2.0 ; p<0.07)$. The ANOVA revealed a significant GROUP $\times$ FINGER interaction $\left(F_{(8,40)}=4.8 ; p<0.01\right)$ as well as a main effect FINGER $\left(F_{(4,40)} \stackrel{=}{=} 8.8 ; p<0.01\right)$ (Fig. 5), indicating that there were different sensory thresholds for the respective fingers and that the extent of this difference was not the same across the groups. Post hoc comparisons between the fingers of the right hand of three-finger readers and the sighted controls revealed a significantly lower threshold for the digits of the three-finger readers: D2 $(t=-3.01 ; p<0.05)$, D4 $(t=-2.7 ; p<$ $0.05)$ and D5 $(t=-3.3 ; p<0.05)$; the group difference for D3 did not reach significance $(t=-2.1 ; p<0.08)$. One-finger readers exhibited lower thresholds in digits D2 $(t=2.3 ; p<0.05)$ and D3 $(t=2.5 ; p<0.05)$ as compared with the sighted controls.

It was also found in each of the three-finger readers that there was a strong tendency to mislocalize which finger was being touched during tactile sensory threshold determination. There was no difficulty in determining that one of the fingers had been 


\section{Distance D1-D5 (cm)}

Figure 2. Distance ( $\mathrm{cm}$ ) between the cortical representation ("center of gravity" determined as ECD-location) of the first (D1, thumb) and fifth (D5, little finger) digits for three-finger blind Braille readers, one-finger blind Braille readers, and sighted controls. $A$, Distance in the inferior-superior dimension (medial/lateral dimension on the surface of the cortex). $B$, Euclidean distance.

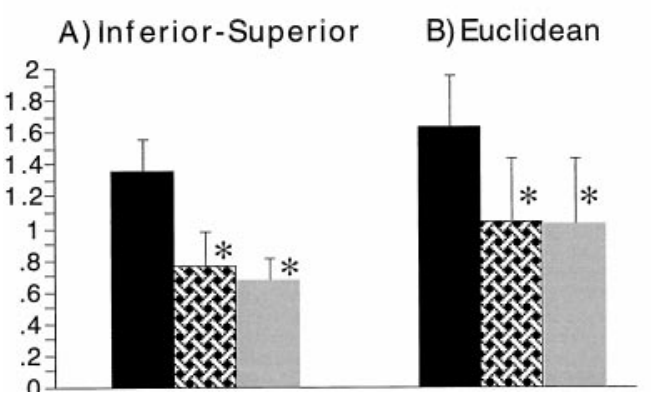

\section{Dipole Moment D2 (nAM)}

three-finger readers Sone-finger readers sighted controls
Figure 3. Dipole moment (nAm) for stimulation of the index finger (D2) of the right hand of the three-finger blind Braille readers, the reading hand of one-finger blind Braille readers (five right, one left), and the right hand in sighted controls as well as the left, nonreading D2s for the three groups.

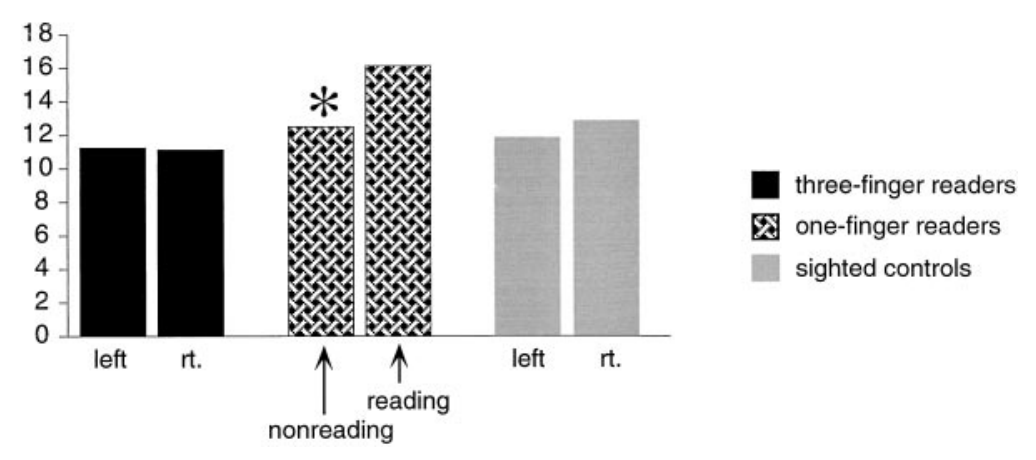

touched, but there was a problem in identifying which one it was. In contrast, none of the sighted subjects and only one of the one-finger readers reported difficulties in determining which of the fingers had been stimulated. If mislocalization on either or both hands is counted as a one and the absence of mislocalizations as a zero, Fisher's exact test (two-tailed) indicates that there is a significant difference between groups $(p=0.005$, for the three groups; $p=0.02$, three-finger vs one-finger readers; $p=$ 0.008 , three-finger readers vs sighted subjects; one-finger readers vs sighted subjects, not significant).

\section{DISCUSSION}

The aim of the present study was to investigate the somatotopic representation of the fingers of blind three-finger Braille readers. In addition, subjects underwent a test in which they had to identify tactile stimuli slightly above individual sensory thresholds to investigate possible perceptual changes. The finding of greatest interest in this study is that the cortical somatosensory representation of the fingers in three-finger Braille readers was often topographically disordered. Another possibility is that the digital representations of the three-finger readers exhibit poor somatotopy, a smearing of the cortical representations, rather than a disorder in the topographic sequencing. Both possibilities are similar, however, in that they represent a departure from normal somatotopy. This could be attributable to the simultaneity of tactile input to the three reading fingers during Braille reading as opposed to the frequently temporally noncoincident tactile stimulation of the fingers (i.e., with a separation of $>20 \mathrm{msec}$ (Allard et al., 1991; Wang et al., 1995). The hands for which cortical topographic disarrangement of digital representation occurred also showed a surprising ten- dency in every case to misperceive which finger was being touched by a light tactile stimulus. The cross-sectional nature of this study does not permit a conclusive determination of causal relationships, but the data are strongly suggestive. Tactile mislocalization clearly has a maladaptive aspect. However, it is interesting to note that for three-finger Braille reading, as for visual reading, it is advantageous to take in a substantial amount of information all at once. It would be more efficient not to have to discriminate separately the nature of the information coming in over the different reading fingers, but for the information to be melded together so that it could be processed as a whole. In this way the "smearing" of the digital cortical representations in three-finger Braille readers would be adaptive. This interpretation receives support from the fact that one-finger Braille reading, which does not require the simultaneous processing of information from different fingers, produces a much lower incidence of such smearing. Thus, it is possible that the smearing in the three-finger readers has a purposive element. Because this process could have value for the individual, learning might enter to elaborate and shape it so that it is most useful for the individual. Another possibility is that the topographic smearing was actually an adventitious effect, whatever the advantageous consequence it had for the efficiency of Braille reading.

It might be noted that the three-finger blind Braille readers read with both hands. The topographic disorder or poor somatotopy and tactile mislocalization occurred for both hemispheres and hands for one subject, but for only one hemisphere and hand for the other three. The reason for the absence of the disorder phenomenon in one hemisphere and mislocalization in the cor- 

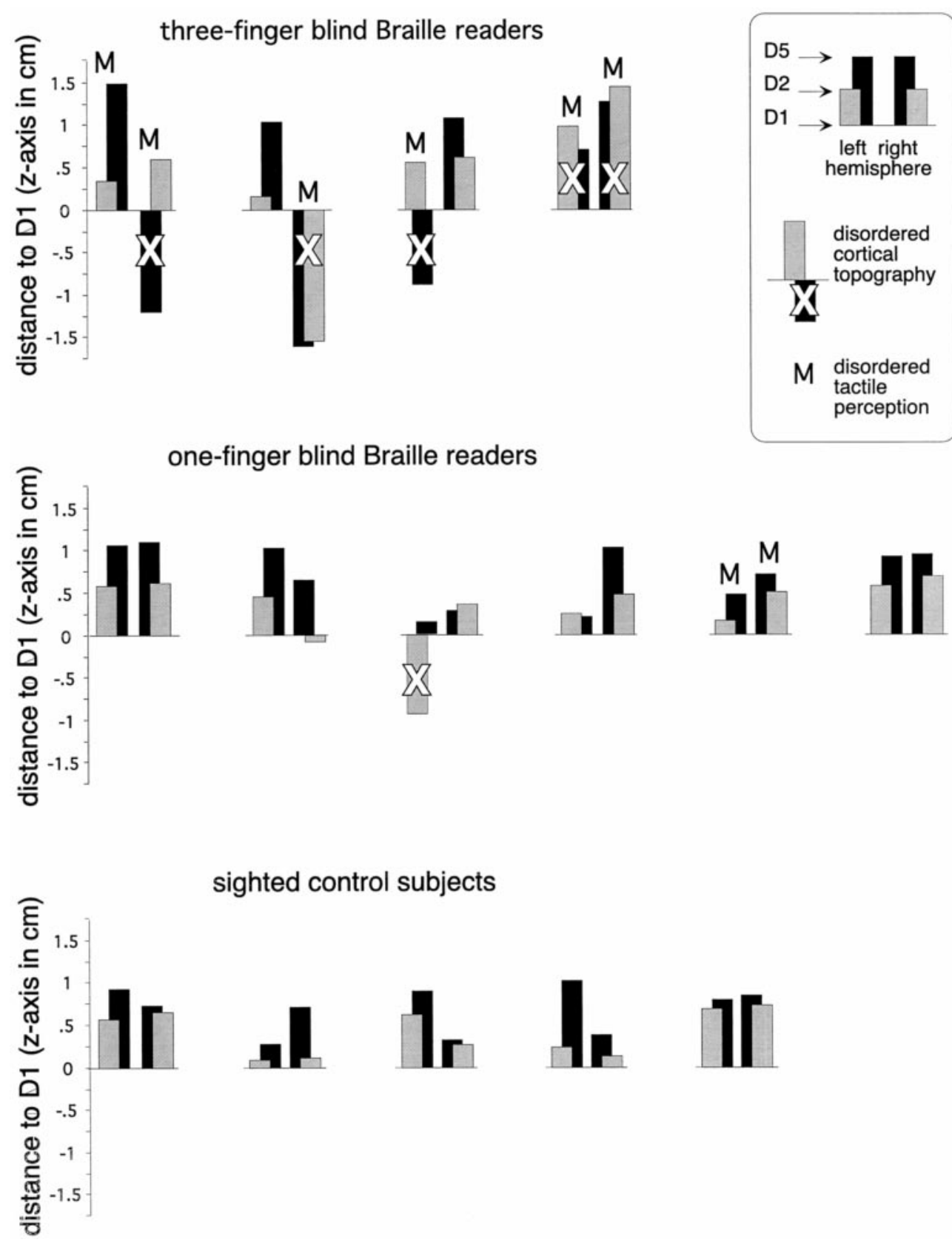

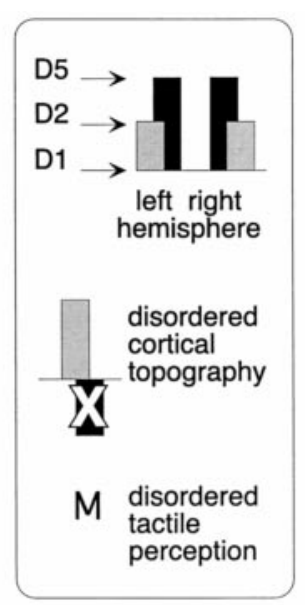

Figure 4. Distance $(\mathrm{cm})$ along the $z$-axis (inferior-superior) between the centers of cortical responsivity for right and left D1, D2, and D5 for each threefinger blind Braille reader, one-finger blind Braille reader, and sighted control subject. $X$ indicates disorganization in the digital topographic arrangement; $M$ indicates tactile mislocalization. Each histogram represents the data from a single subject, with the topographic digital representation of the left and right hemispheres shown separately. The black bar represents the distance along the $z$-axis from the representation of D1 to that of D5. The gray bar represents the distance from D2 to D5. The two bars on the left are for the left hemisphere and the two bars on the right are for the right hemisphere. The data for the two onefinger readers who used the left hand are presented in the first and second histograms of the middle row. responding hand for these three subjects could have to do with such individual differences during Braille reading as amount of force exerted with the digits of the two hands, bimanual difference in amount of isometric tension, differences in postural adjustments of the two arms and hands, differences in the attention paid to the information coming from the two hands, etcetera; there might also be differences in the structural or functional organization of the two hemispheres that could account for the observed differences. The important consideration, though, is that when there was hemispheric digital topographic disorder, there was also tactile mislocalization in the contralateral hand.

One of the three-finger Braille readers became blind and learned Braille reading when an adult. This was also the case for two of the one-finger blind Braille readers, whereas a third, who became blind when 7 years of age, did not learn Braille reading until he was 20 . Therefore, the data indicate that both the alteration in cortical topography and the enlargement of cortical digital representations can occur in adulthood; they do not take place only when the nervous system is immature.

This study also indicates that the somatosensory representation of the fingers in three-finger blind Braille readers is enlarged. This confirms the previous observation in animals (Recanzone et al., 1992a-c), in sighted Braille readers (Rockstroh et al., 1998), and for the left hand in string players (Elbert et al., 1995) that the cortical somatosensory representation of the hand (and presumably other portions of the body) is plastic and responds to increases in use of that body part with an expansion in size. It also confirms the observation that the motor representation of a reading finger in blind Braille readers can be enlarged (PascualLeone et al., 1993). The enlarged finger representation is clearly 
LEFT- / CONTROLHAND

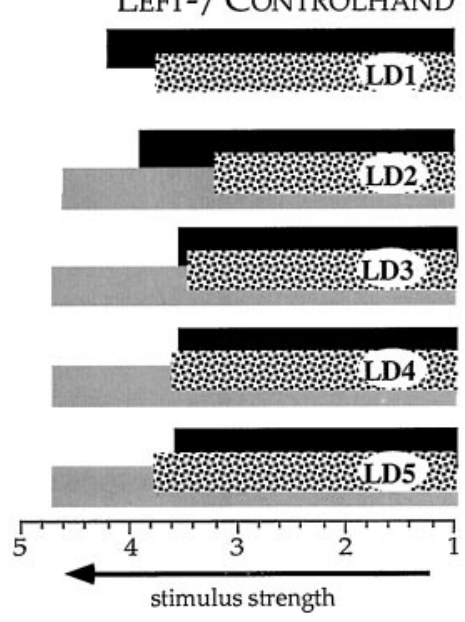

RIGHT-/READINGHAND

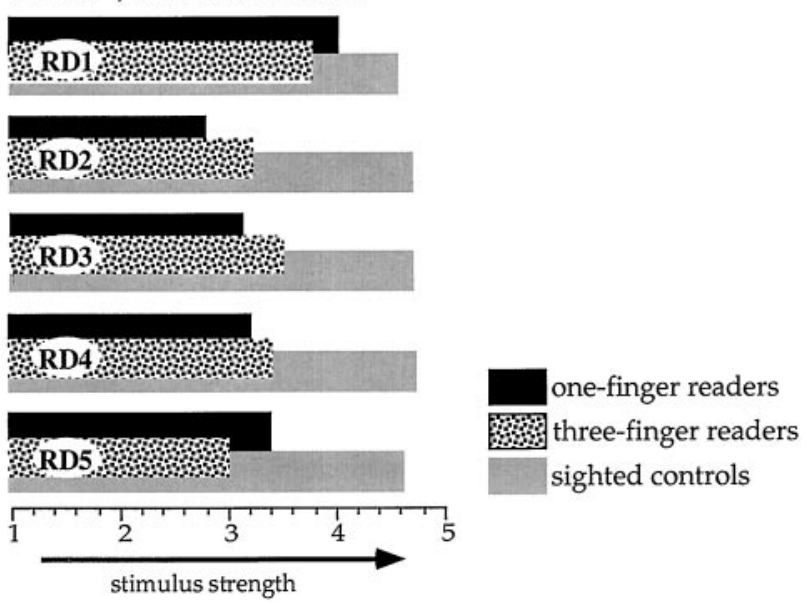

Figure 5. Absolute tactile thresholds (in von Frey hair strengths) for each of the digits of the three-finger blind Braille readers, the one-finger blind Braille readers, and the sighted control subjects. the result of the increase in behaviorally relevant sensory input during Braille reading. It is possible that this enlargement in turn aids in the appreciation of the Braille letters, although data are not currently available to determine whether this is the case.

A more general question concerns the role of cortical reorganization in the functional economy of the organism. After upper extremity amputation, phantom limb pain has been shown to have a very strong relationship to cortical reorganization (Flor et al., 1995). Tinnitus, which may also be caused by neurological injury, is similarly strongly correlated with cortical reorganization (Mühlnickel et al., 1998), as are chronic lower back pain (Flor et al., 1997) and focal dystonia (Elbert et al., 1996). Each of these conditions is highly aversive. In the present paper, it has been shown that changes in cortical representation resulting from increases in peripheral input can be associated with a nonadaptive phenomenon (i.e., digital tactile mislocalization), but it is also possible that the "smearing" of the topographic arrangement of the digital cortical representation in blind Braille readers is associated with an adaptive phenomenon as well (i.e., a fusion in the incoming digital information), which would make reading more efficient. A significant issue that remains to be resolved by future research is whether cortical reorganization after neurological injury can be related to positive outcomes as well as to the aversive conditions noted above. The candidate process that is potentially of greatest importance is the recovery of function after damage to the nervous system.

\section{REFERENCES}

Allard T, Clark SA, Jenkins WM, Merzenich MM (1991) Reorganization of somatosensory area $3 \mathrm{~b}$ representations in adult owl monkeys after digital syndactyly. J Neurophysiol 66:1048-1058.

Birbaumer N, Lutzenberger W, Monotya P, Larbig W, Unertl K, Töpfner S, Grodd W, Taub E, Flor H (1997) Effects of regional anesthesia on phantom limb pain are mirrored in changes in cortical reorganization. J Neurosci 17:5503-5508.

Byl NN, Merzenich MM, Jenkins WM (1996) A primate genesis model of focal dystonia and repetitive strain injury: I. Learning-induced dedifferentiation of the representation of the hand in the primary somatosensory cortex in adult monkeys. Neurology 47:508-520.

Byl NN, Merzenich MM, Cheung S, Bodenbaugh P, Nagarajan SS, Jenkins WM (1997) A primate model for studying focal dystonia and repetitive strain injury: effects on the primary somatosensory cortex. Phys Ther 77:269-284.
Clark SA, Allard T, Jenkins WM, Merzenich MM (1988) Receptive fields in the body-surface map in adult cortex defined by temporally correlated inputs. Nature 332:444-445.

Elbert T, Flor H, Birbaumer N, Knecht S, Hampson S, Larbig W, Taub E (1994) Extensive reorganization of the somatosensory cortex in adult humans after nervous system injury. NeuroReport 5:2593-2597.

Elbert T, Pantev C, Wienbruch C, Hoke M, Rockstroh B, Taub E (1995) Increased use of the left hand in string players associated with increased cortical representation of the fingers. Science 220:21-23.

Elbert T, Sterr A, Candia C, Rockstroh B, Taub E (1996) Representational cortical plasticity as revealed by magnetic source imaging: how the brain learns to play the violin. First Berlin Workshop On Cortical Plasticity, Berlin, November.

Elbert T, Sterr A, Flor H, Rockstroh B, Knecht S, Pantev C, Wienbruch C, Taub E (1997) Input-increase and input-decrease types of cortical reorganization after upper limb extremity amputation in humans. Exp Brain Res 117:161-164.

Flor H, Elbert T, Knecht S, Wienbruch C, Pantev C, Birbaumer N, Larbig W, Taub E (1995) Phantom-limb pain as a perceptual correlate of cortical reorganization following arm amputation. Nature 375:482-484.

Flor H, Braun C, Elbert T, Birbaumer N (1997) Extensive reorganization of primary somatosensory cortex in chronic back pain. Neurosci Lett 224:5-8.

Florence SL, Kaas JH (1995) Large-scale reorganization at multiple levels of the somatosensory pathway follows therapeutic amputation of the hand in monkeys. J Neurosci 15:8083-8095.

Jenkins WM, Merzenich MM, Ochs MT, Allard T, Guic-Robles E (1990) Functional reorganization of primary somatosensory cortex in adult owl monkeys after behaviorally controlled tactile stimulation. J Neurophysiol 63:82-104.

Knecht S, Henningsen H, Elbert T, Flor H, Hoehling C, Pantev C, Taub E (1996) Reorganizational and perceptual changes after amputation. Brain 119:1213-1219.

Merzenich MM, Nelson RJ, Stryker MP, Cynader MS, Schoppmann A, Zook JM (1984) Somatosensory cortical map changes following digit amputation in adult monkeys. J Comp Neurol 224:591-605.

Mogilner A, Grossman JAI, Ribary U, Joliot M, Volkmann J, Rapaport D, Beasley RW, Llinas RR (1993) Somatosensory cortical plasticity in adult humans revealed by magnetoencephalograhy. Proc Natl Acad Sci USA 90:3593-3597.

Mühlnickel W, Elbert T, Taub E, Flor H (1998) Deviations from the tonotopic map are correlated with tinnitus strength. In: Advances in biomagnetism research: Biomag96, Vol II Aine C, Okada Y, Stroink G, Swithenby S, Wood C, (eds). New York: Springer-Verlag.

Pascual-Leone A, Cammarota A, Wassermann EM, Brasil-Neto JP, Cohen LG, Hallett M (1993) Modulation of motor cortical outputs to the reading hand of Braille readers. Ann Neurol 34:33-37.

Pons TP, Garraghty PE, Ommaya AK, Kaas JH, Taub E, Mishkin M (1991) Massive cortical reorganisation after sensory deafferentation in adult macaques. Science 252:1857-1860.

Recanzone G, Allard TT, Jenkins WM, Merzenich MM

(1990) 
Receptive-field changes induced by peripheral nerve stimulation in SI of adult rats. J Neurophysiol 63:1213-1225.

Recanzone GH, Jenkins WM, Hradek GT, Merzenich MM (1992a) Progressive improvement in discriminative abilities in adult owl monkeys performing a tactile discrimination task. J Neurophysiol 67:1015-1030.

Recanzone GH, Merzenich MM, Jenkins WM (1992b) Frequency discrimination training engaging a restricted skin surface results in an emergence of a cutaneous response zone in cortical area 3a. J Neurophysiol 67:1057-1070.

Recanzone GH, Merzenich MM, Jenkins WM, Grajski KA, Dinse HR (1992c) Topographic reorganization of the hand representation in cortical area $3 \mathrm{~b}$ of owl monkeys trained in a frequency-discrimination task. J Neurophysiol 67:1031-1056.
Rockstroh B, Vanni S, Elbert T, Hari R (1998) Extensive somatosensory stimulation alters somatosensory evoked fields. In: Advances in biomagnetism research: Biomag96 International Conference on Biomagnetism. Aine C, Okada Y, Stroink G, Swithenby S, Wood C, (eds). New York: Springer-Verlag.

Sterr A, Müller MM, Elbert T, Rockstroh B, Pantev C, Taub E (1998) Changed perception in Braille-readers. Nature 1998:134-135.

Wang X, Merzenich MM, Sameshima K, Jenkins WM (1995) Remodelling of hand representation in adult cortex determined by timing of tactile stimulation. Nature 378:71-75.

Yang TT, Gallen CC, Ramachandran VS, Cobb S, Schwartz BJ, Blum FB (1994) Noninvasive detection of cerebral plasticity in adult human somatosensory cortex. NeuroReport 5:701-704. 